Original Article

\title{
ASI Eksklusif dan Imunisasi Berhubungan dengan Kejadian Stunting pada Anak Usia 9-24 Bulan di Puskesmas Rumah Tiga, Ambon
}

\section{Exclusive breastfeeding and immunization are related to stunting in children aged 9-24 months at Rumah Tiga Health Center, Ambon}

\author{
EIpira Asmin, Mujahidah Rofifah Abdullah \\ Prodi Pendidikan Dokter, Fakultas Kedokteran, Universitas Pattimura, Indonesia
}

(elpiraasmin@gmail.com, 08114111724)

\begin{abstract}
ABSTRAK
Stunting adalah kondisi gagal tumbuh pada anak yang ditandai dengan tinggi badan tidak sesuai dengan usia akibat kekurangan gizi kronis terutama dalam 1000 Hari Pertama Kehidupan (HPK), yaitu sejak di kandungan ibu sampai usia anak dua tahun. Berdasarkan data dari Riskesdas 2018 Provinsi Maluku, prevalensi stunting ialah $34,02 \%$. Tujuan penelitian ini adalah untuk mengetahui hubungan ASI Eksklusif dan Imunisasi dengan kejadian stunting pada anak di Puskesmas Rumah Tiga Kota Ambon. Penelitian ini merupakan pengolahan data sekunder dengan pendekatan cross sectional. Sampel yang digunakan dalam penelitian ini adalah anak usia 9-24 bulan yang terdata di Puskesmas Rumah Tiga pada tahun 2019-2020 berjumlah 559 anak. Hasil penelitian menunjukan dari 559 anak yang menjadi sampel penelitian, $27,2 \%$ anak mengalami stunting dan $72,8 \%$ tidak mengalami stunting. ASI Eksklusif dan imunisasi berhubungan dengan kejadian stunting. ASI Eksklusif memiliki cakupan yang masih rendah. Diharapkan adanya program pendampingan untuk ibu menyusui, agar dapat meningkatkan pemberian ASI Eksklusif dan pemberian ASI hingga anak usia 2 tahun. Hal ini setidaknya dapat membantu mencegah stunting pada anak di Puskesmas Rumah Tiga, Ambon.
\end{abstract}

Kata kunci : Stunting, ASI Eksklusif, Imunisasi,

\section{ABSTRACT}

Stunting is a condition of failure to thrive in children characterized by height that is not appropriate for age due to chronic malnutrition, especially in the First 1000 Days of Life, which is from the mother's womb until the child is two years old. Based on data from Riskesdas 2018, Maluku Province, the prevalence of stunting is $34.02 \%$. The purpose of this study was to determine the relationship between exclusive breastfeeding and immunization with the incidence of stunting in children at Rumah Tiga Health Center, Ambon City. This research is secondary data processing with cross sectional approach. The sample used in this study was children aged 9-24 months who were recorded at the Rumah Tiga Health Center in 2019-2020 totaling 559 children. The results showed that of the 559 children who were the research sample, $27.2 \%$ of children were stunted and $72.8 \%$ were not stunted. Exclusive breastfeeding and immunization are associated with stunting. Exclusive breastfeeding has a low coverage. It is hoped that there will be a mentoring program for breastfeeding mothers, in order to increase exclusive breastfeeding and breastfeeding for children aged 2 years. This can at least help prevent stunting in children at the Rumah Tiga Health Center, Ambon.

Keywords : Stunting, Exclusive breastfeeding, Immunization,

https://doi.org/10.33860/jik.v15i2.487

(C) 2021 by the authors. Submitted for possible open access publication under the terms and conditions of the Creative

Commons Attribution (CC BY SA) license (https://creativecommons.org/licenses/by-sa/4.0/). 


\section{PENDAHULUAN}

Asupan zat gizi pada anak-anak merupakan hal yang sangat penting, sehingga perlu mendapatkan perhatian khusus, terutama pada usia 0-24 bulan atau 1000 hari pertama kehidupan ${ }^{1}$. Masalah gizi yang sangat perlu diperhatikan pada anak usia 6-12 bulan yang juga merupakan permasalahan anak paling banyak di Indonesia adalah stunting ${ }^{1,2}$. Stunting atau kekerdilan sebagai salah satu prioritas Rancangan Pembangunan Jangka Menengah Nasional (RPJMN) adalah kondisi gagal tumbuh pada anak yang ditandai dengan tinggi badan tidak sesuai dengan usia akibat kekurangan gizi kronis terutama dalam 1000 Hari Pertama Kehidupan (HPK), yaitu sejak di kandungan ibu sampai usia anak dua tahun ${ }^{3,4}$.

\section{Stunting merupakan kondisi kronis} yang menggambarkan terhambatnya pertumbuhan karena malnutrisi jangka panjang dan manifestasi lebih lanjut akibat Berat Bayi Lahir Rendah (BBLR) dan kurang gizi pada masa anak serta tidak adanya pencapaian perbaikan pertumbuhan (catch-up growth) yang sempurna pada masa berikutnya 5,6,7. Bayi dengan BBLR mengalami pertumbuhan dan perkembangan lebih lambat sejak dalam kandungan karena retardasi pertumbuhan interauterin dan kelahiran prematur. Hal ini dapat berlanjut hingga anak telah lahir jika tidak didukung dengan pemberian gizi dan pola asuh yang baik, di mana akhirnya sering gagal mengejar tingkat pertumbuhan yang seharusnya dia capai pada usianya ${ }^{6,8,9,10}$.

Kekurangan gizi pada masa anak sebagai faktor utama penyebab terjadinya stunting juga berkaitan dengan ASI Eksklusif 2,3,5. Berdasarkan Peraturan Pemerintah Nomor 33 Tahun 2012, ASI Eksklusif adalah ASI yang diberikan kepada bayi sejak dilahirkan sampai usia enam bulan tanpa menambahkan dan mengganti dengan makanan atau minuman lain, kecuali suplemen vitamin, obat, dan mineral ${ }^{11}$. ASI Eksklusif memiliki kontribusi yang besar dalam pemenuhan asupan gizi bayi, yang akan berdampak dalam tumbuh kembang (psikomotor, kognitif, sosial), dan daya tahan tubuh ${ }^{11,12,13}$.
Selain berhubungan dengan defisiensi gizi (mikronutrien dan makronutrien), diketahui dari beberapa hasil penelitian bahwa infeksi dapat menyebabkan stunting ${ }^{14}$. Salah satu langkah dalam mencegah penyakit infeksi pada anak-anak dapat dilakukan dengan cara memberikan imunisasi. Imunisasi adalah suatu upaya untuk menimbulkan/meningkatkan kekebalan seseorang secara aktif terhadap suatu penyakit ${ }^{14}$.

Data World Health Organization (WHO) tahun 2017 didapatkan hasil bahwa stunting secara global mempengaruhi sekitar $22,2 \%$ atau 150,8 juta anak dibawah usia lima tahun ${ }^{3}$. Data Riskesdas 2018, prevalensi stunting pada anak secara nasional tahun 2018 adalah $30,8 \%$, di mana menurut standar WHO prevalensi stunting di Indonesia dianggap berat karena berada pada kisaran $30-39 \%{ }^{3,15}$. Di Maluku, prevalensi stunting 34,02\% dan Ambon sebesar $31,26 \%{ }^{15}$. Sedangkan pada tahun 2019, Dinas Kesehatan (Dinkes) Kota Ambon, Puskesmas Rumah Tiga memiliki anak gizi kurang sebanyak $8,2 \%$ dan stunting sebanyak $5,8 \%{ }^{16}$.

Pertumbuhan fisik dan intelektualitas anak akan mengalami gangguan, bila asupan zat gizi tidak terpenuhi. Hal ini akan menyebabkan mereka menjadi generasi yang hilang (lost generation), dan berdampak pada kehilangannya Sumber Daya Manusia (SDM) di suatu negara ${ }^{2,13}$. Oleh sebab itu, pentingnya untuk setiap anak mendapatkan gizi dengan maksimal, untuk mencegah dari berbagai gangguan gizi, salah satunya yaitu stunting.

Penelitian ini bertujuan untuk mengetahui hubungan ASI Eksklusif dan Imunisasi dengan kejadian stunting di Puskesmas Rumah Tiga, Ambon.

\section{METODE PENELITIAN}

Penelitian ini merupakan penelitian kuantitatif, jenis penelitian analitik observasional dengan rancangan cross sectional. Lokasi penelitian di Puskesmas Rumah Tiga, Ambon.

Sampel dalam penelitian ini adalah anak usia 9-24 bulan yang tercatat di data Puskesmas 
Rumah tiga yang berjumlah 559 anak. Kriteria inklusi yaitu anak usia 9-24 bulan, memiliki data tinggi badan, data BBLR, ASI Eksklusif dan Imunisasi. Adapun kriteria eksklusi yaitu anak yang tidak memiliki data lengkap di buku register Puskesmas, dan anak yang lahir dengan BBLR dan kurang bulan atau prematur.

Data dianalisis menggunakan software SPSS versi 24. Analisis bivariat dalam penelitian ini menggunakan uji statistik $c h i$ square.

\section{HASIL}

Distribusi frekuensi anak berdasarkan jenis kelamin berdasarkan tabel 1, menunjukkan persentase terbanyak pada jenis kelamin lakilaki (50,3\% atau 281 anak) dibandingkan perempuan (49,7\% atau 278 anak). Distribusi anak berdasarkan kejadian stunting adalah sebanyak 27 persen anak yang mengalami kejadian stunting, sedangkan 73 persen anak yang lainnya tidak mengalami stunting.

Tabel 1 menunjukkan bahwa anak yang mendapatkan ASI Eksklusif hanya sekitar 23 persen dan sisanya tidak mendapatkan ASI Eksklusif. Anak yang diberikan imunisasi lebih banyak dibandingkan dengan yang tidak imunisasi. Di mana sebanyak 83 persen anak memperoleh imunisasi.

Tabel 1 Karakteristik Anak Usia 9-24 Bulan di Puskesmas Rumah Tiga

\begin{tabular}{lcc}
\hline Karakteristik & n & \% \\
\hline Jenis Kelamin & & \\
Laki-laki & 281 & 50,3 \\
Perempuan & 278 & 49,7 \\
Stunting & & \\
Ya & 152 & 27,2 \\
Tidak & 407 & 72,8 \\
ASI Eksklusif & & \\
Ya & 128 & 22,9 \\
Tidak & 431 & 77,1 \\
Imunisasi & & \\
Ya & 464 & 83,0 \\
Tidak & 95 & 17,0 \\
\hline
\end{tabular}

Tabel 2 Hasil Analisis Bivariat

\begin{tabular}{|c|c|c|c|c|c|c|c|}
\hline \multirow{3}{*}{ Variabel } & \multicolumn{4}{|c|}{ Stunting } & \multirow{2}{*}{\multicolumn{2}{|c|}{ Total }} & \multirow{3}{*}{$p$} \\
\hline & \multicolumn{2}{|c|}{$\mathrm{Ya}$} & \multicolumn{2}{|c|}{ Tidak } & & & \\
\hline & $\mathrm{n}$ & $\%$ & $\mathrm{n}$ & $\%$ & $\mathrm{n}$ & $\%$ & \\
\hline \multicolumn{8}{|l|}{ ASI Eksklusif } \\
\hline $\mathrm{Ya}$ & 20 & 15,6 & 108 & 84,4 & 128 & 100 & 0,001 \\
\hline Tidak & 132 & 30,6 & 299 & 69,4 & 431 & 100 & \\
\hline \multicolumn{8}{|l|}{ Imunisasi } \\
\hline $\mathrm{Ya}$ & 117 & 25,2 & 347 & 74,8 & 464 & 100 & 0,020 \\
\hline Tidak & 35 & 36,8 & 60 & 63,2 & 95 & 100 & \\
\hline
\end{tabular}

Tabel 2 menunjukkan anak mengalami stunting 16 persen yang diberikan ASI Eksklusif dan sebesar 31 persen tidak diberikan. Hasil analisis data menyatakan ada hubungan ASI Eksklusif dengan kejadian stunting. Selain itu, dapat dilihat juga bahwa anak yang mengalami stunting hanya 25 persen yang mendapatkan imunisasi dan sebanyak 37 persen yang tidak diimunisasi. Hasil analisis menunjukkan bahwa ada hubungan Imunisasi dengan kejadian stunting.
PEMBAHASAN

\section{Hubungan ASI Eksklusif dengan Kejadian Stunting}

ASI Eksklusif merupakan asupan nutrisi yang paling baik pada 6 bulan pertama kehidupan anak. Oleh karena itu, untuk memenuhi kebutuhan asupan gizi pada bayi dan untuk mencegah terjadinya stunting pada anak kelak dapat diberikan ASI Eksklusif. Hal ini sejalan dengan penelitian yang dilakukan oleh Yuyun Sarinengsih ${ }^{17}$ dan Eka Maulana Agustin $^{18}$ tahun 2019 yang menyatakan bahwa ada hubungan ASI Eksklusif dengan kejadian 
stunting pada anak. Selain itu, hasil ini juga sejalan dengan penelitian yang dilakukan oleh Farah Okky Aridiyah, dkk ${ }^{19}$ pada tahun 2015 yang mengungkapkan bahwa kejadian stunting pada anak baik yang berada di wilayah pedesaan maupun perkotaan di pengaruhi oleh pemberian ASI Eksklusif.

Penelitian ini menemukan bahwa cakupan pemberian ASI Eksklusif pada bayi 0-6 bulan masih tergolong rendah. Hal ini sangat disayangkan, mengetahui bahwa pemberian ASI Eksklusif merupakan salah satu faktor pelindung terhadap stunting pada anak ${ }^{20,21}$. Rendahnya pemberian ASI Eksklusif pada anak dapat dipengaruhi oleh faktor pendidikan, pengetahuan, sikap dan perilaku, faktor psikologis, faktor fisik dan emosional $\mathrm{ibu}^{17}$. Rendahnya pemberian ASI Eksklusif pada anak di Puskesmas Rumah Tiga disebabkan oleh faktor fisik ibu atau kurangnya pengetahuan keluarga terdekat mengenai ASI Eksklusif. Selain itu, ibu menyusui sering mengalami hambatan berupa tidak keluarnya ASI, yang pada akhirnya memberikan susu formula kepada anaknya ditambah lagi banyak dari keluarga terdekat sering kali memberikan makanan yang seharusnya belum dikonsumsi oleh anak. Rendahnya cakupan ASI Eksklusif tentunya memberikan sumbangsih pada kejadian stunting pada anak di Puskesmas Rumah Tiga, Ambon.

\section{Hubungan Imunisasi dengan Kejadian Stunting}

Setiap anak usia 0-9 bulan seyogiyanya telah diberikan imunisasi dasar lengkap. Hal ini sangat bermanfaat untuk membentuk kekebalan tubuh bayi sehingga dapat terlindungi dari berbagai jenis penyakit infeksi. Penyakit infeksi yang diderita oleh anak dapat menghambat penyerapan nutrisi secara optimal di dalam tubuh. Hal tersebut dapat menyebabkan terjadinya stunting pada anak. Hal ini sejalan dengan penelitian yang dilakukan oleh Agus Hendra Al-Rahmad, dkk ${ }^{22}$ pada tahun 2013 dan Dandara Swathma, $\mathrm{dkk}^{23}$ pada tahun 2016 yang menyatakan bahwa ada hubungan imunisasi dengan kejadian stunting pada anak. Penelitian lain juga menemukan bahwa status imunisasi merupakan salah satu faktor risiko stunting ${ }^{24,25}$. Cakupan imunisasi pada anak di Puskesmas Rumah Tiga terbilang sudah cukup baik. Dengan banyaknya anak yang mendapatkan imunisasi, maka akan semakin rendah tingkat kejadian stunting. Pemberian imunisasi meminimalisir PD3I pada anak, sehingga pertumbuhan dan perkembangan anak lebih optimal. Diketahui bahwa infeksi akan menghambat reaksi imunologis yang normal dengan menghabiskan energi tubuh ${ }^{22}$. Selain itu, adanya infeksi menyebabkan penurunan nafsu makan anak, sehingga asupan makanan untuk tumbuh kembang semakin berkurang. Berdasarkan hal tersebut dapat dikatakan bahwa salah satu upaya untuk mengurangi angka kejadian stunting adalah dengan memberikan imunisasi secara lengkap pada anak.

\section{KESIMPULAN DAN SARAN}

ASI Eksklusif dan imunisasi berhubungan dengan kejadian stunting. ASI Eksklusif memiliki cakupan yang masih rendah. Diharapkan adanya program pendampingan untuk ibu menyusui, agar dapat meningkatkan pemberian ASI Eksklusif dan pemberian ASI hingga anak usia 2 tahun. Hal ini setidaknya dapat membantu mencegah stunting pada anak di Puskesmas Rumah Tiga, Ambon.

\section{UCAPAN TERIMA KASIH}

Ucapan terima kasih kami sampaikan kepada 1) Fakultas Kedokteran Universitas Pattimura, 2) Pihak Puskesmas Rumah Tiga, Ambon, 3) Dinas Kesehatan Kota Ambon.

\section{DAFTAR PUSTAKA}

1. Permadi MR, Hanim D, Kusnandar K, Indarto D. Risiko Inisiasi Menyusu Dini Dan Praktek Asi Eksklusif Terhadap Kejadian Stunting Pada Anak 6-24 Bulan (Early Breastfeeding Initiation and Exclusive Breastfeeding As Risk Factors of Stunting Children 6-24 Months-Old). Penelit Gizi dan Makanan (The J Nutr Food Res. 2017;39(1):9-14.

2. Sari DF, Oktacia R. Gambaran Faktor Risiko Kejadian Stunting Pada Anak Di Wilayah 
Kerja Puskesmas Nangalo Kota Padang. J Kesehat Mercubaktijaya. 2018;1(1).

3. Annisa N, Sumiaty S, Tondong HI. Hubungan Inisiasi Menyusu Dini dan ASI Eksklusif dengan Stunting pada Baduta Usia 7-24 Bulan. J Bidan Cerdas. 2019;2(2):92.

4. Yuliawati E, Sulung N, Hasnita E. Inisiasi Menyusui Dini, Keanekaragaman Makanan dan Jaminan Kesehatan Terhadap Kejadian Stunting. J Hum Care [Internet]. 2019;4(3):132-7. Available from: enituliawati12@gmail.com

5. Sari EM. Hubungan riwayat BBLR dengan kejadian stunting pada anak usia 7-12 bulan di Desa Selomartani wilayah kerja Puskesmas Kalasan. Universitas 'Aisyiyah Yogyakarta; 2017.

6. Dewi NT, Widari D. Hubungan Berat Badan Lahir Rendah dan Penyakit Infeksi dengan Kejadian Stunting pada Baduta di Desa Maron Kidul Kecamatan Maron Kabupaten Probolinggo The Relationship Between Low Birth Weight and Infection Disease with Stunting among Children Under Two Ye. Porbolinggo; 2018.

7. Sundari RM. Hubungan Berat Badan Lahir Rendah (BBLR) dan perilaku pemberian ASI Eksklusif dengan kejadian Stunting Baduta di Puskesmas Sangkrah Kota Surakarta. Universitas Muhammadiyah Surakarta; 2018.

8. Nasution D, Nurdiati DS, Huriyati E. Jurnal Gizi Klinik Indonesia Berat badan lahir rendah ( BBLR ) dengan kejadian stunting pada anak usia 6-24 bulan. 2014;11(01):317.

9. Fitri L. Hubungan BBLR dan ASI Eksklusif dengan kejadian stunting di Puskesmas Lima Puluh Pekanbaru. J Endur. 2018;3(1):131-7.

10. Putra O. Pengaruh BBLR terhadap kejadian stunting pada anak usia 12-60 bulan di wilayah kerja Puskesmas Pauh pada tahun 2015. Universitas Andalas; 2016.

11. Irawan J. Hubungan Inisiasi Menyusu Dini ( IMD ) dan pemberian Air Susu Ibu ( ASI ) Eksklusif DI RSUD Wangaya. Skala Husada [Internet]. 2018;5(1):1-7. Available from: http://ejournal.poltekkes-

denpasar.ac.id/index.php/JSH/article/downl oad $/ 218 / 89$

12. Angelina C, Perdana AA, Humairoh $\mathrm{H}$. Faktor kejadian stunting anak berusia 6-23 bulan di Provinsi Lampung. J Dunia Kesmas. 2018;7(3):127-34.

13. Kody MM. Pengaruh Pemanfaatan ASI Kolostrum Terhadap Timbulnya Penyakit Infeksi Pada Bayi Usia 7-11 Bulan Di Wilayah Kerja Puskesmas Kambaniru Waingapu Kabupaten Sumba Timur. J Info Kesehat. 2016;14(2):1258-69.

14. Sumardilah DS, Rahmadi A. Risiko Stunting Anak Baduta (7-24 bulan). J Kesehat. 2019;10(1):93.

15. Lembaga Penerbit Badan Litbang Kesehatan 2019. Laporan Provinsi Maluku Riskesdas 2018. Indonesia: Kemenkes RI; 2019. 442 p. Dinas Kesehatan Kota Ambon. Data Puskesmas Ambon. Ambon; 2019.

17. Sarinengsih Y. Hubungan Pemberian Asi Eksklusif dengan Kejadian Stunting pada Anak Usia 1- 5 Tahun di Puskesmas Sukahening Kecamatan Sukahening Kabupaten Tasikmalaya. J Ilmu Kesehat. 2019;13(2):109-17.

18. Agustin EM. Hubungan pemberian ASI Eksklusif dan Status Imunisasi dengan kejadian stunting pada anak usia 2-5 tahun di Desa Karangturi Kecamatan Glagah Kabupaten Lamongan [Internet]. Universitas Muhammadiyah Lamongan. Universitas Muhammadiyah Lamongan; 2019. Available from: http://www.repository.umla.ac.id/1066/1/ba gian awal.pdf

19. Aridiyah FO, Rohmawati N, Ririanty M. Faktor-faktor yang mempengaruhi kejadian stunting pada ana anak di wilayah pedesaan dan perkotaan. JAOCS, J Am Oil Chem Soc. 2015;3(1):163-70.

20. Lestari E, Hasanah F, Nugroho N. Correlation between non-exclusive breastfeeding and low birth weight to stunting in children. 2018;58(3):123-. Available from: https://paediatricaindonesiana.org/index.ph p/paediatrica-indonesiana/article/view/1140

21. Sirajuddin, Nursalim AT. Breastfeeding practices can potential to prevent stunting for poor family. Enfermería Clínica [Internet]. 2020;30:13-7. Available from: https://doi.org/10.1016/j.enfcli.2020.02.007

22. AL Rahmad AH, Miko A, Hadi A. Kajian Stunting Pada Anak Anak Ditinjau Dari Pemberian ASI Eksklusif, MP-ASI, Status Imunisasi Dan Karakteristik Keluarga Di Kota Banda Aceh. J Kesehat Ilm Nasuwakes 
Poltekkes Aceh. 2013;6(2):169-84.

23. Swathma D, Lestari H, Ardiansyah R. Analisis Faktor Risiko Bblr, Panjang Badan Bayi Saat Lahir Dan Riwayat Imunisasi Dasar Terhadap Kejadian Stunting Pada Anak Usia 12-36 Bulan Di Wilayah Kerja Puskesmas Kandai Kota Kendari Tahun 2016. Vol. 1, Jurnal Ilmiah Mahasiswa Kesehatan Masyarakat Unsyiah. 2016.

24. Andrea Wendt, Franciele Hellwig, Ghada E. Saad, Cheikh Faye, Zitha Mokomane, Ties Boerma, Aluisio J.D. Barros, Cesar Victora. Are children in female-headed households at a disadvantage? An analysis of immunization coverage and stunting prevalence: in 95 low- and middle-income countries, SSM - Population Health,Volume 15, 2021, 100888, ISSN 2352-8273, https://doi.org/10.1016/j.ssmph.2021.10088 8.

25. Miranti, Diah Mutiarasari, A. Arsunan Arsin, Veny Hadju, Anwar Mallongi, Rosmala Nur, Imtihanah Amri, Haerani Haruni, Rosa Dwi Wahyuni, Rahma, Abdul Faris, Determinants of the incidence of stunting in the working area of Kinovaro Sigi Health Center, Enfermería Clínica,Volume 30, Supplement 4, 2020, Pages 246-252, ISSN 1130-8621, https://doi.org/10.1016/j.enfcli.2019.10.077 